\title{
Simultaneous Scheduling of Machines and AGVs in FMS Through Ant Colony Optimization Algorithm
}

\author{
M. Nageswara Rao, S. Vara Kumari, P. Manohar, B. Madesh, P. Naveen Krishna, \\ R. Suraj Krishna Sai
}

\begin{abstract}
High amount of flexibility and quick response times have become essential features of modern manufacturing systems where customers are demanding a variety of products with reduced product life cycles. Flexible manufacturing system (FMS) is the right choice to achieve these challenging tasks. The performance of FMS is dependent on the selection of scheduling policy of the manufacturing system. In Traditional scheduling problems machines are as considered alone. But material handling equipment's are also valuable resources in FMS. The scheduling of AGVs is needed to be optimized and harmonized with machine operations. Scheduling in FMS is a well-known NP-hard problem due to considerations of material handling and machine scheduling. Many researchers addressed machine and AGVs individually. In this work an attempt is made to schedule both the machines and AGVs simultaneously. For solving these problems-a new metaheuristic Ant Colony Optimization (ACO) algorithm is proposed.
\end{abstract}

Keywords : FMS; Operational Completion Time (makespan); Metaheuristic algorithms; AGVs; NP-hard problems.

\section{INTRODUCTION}

A Flexible Manufacturing System (FMS) is a highly automated manufacturing system well suited for the simultaneous production of a wide variety of part types in low to mid volume quantities at a low cost while maintaining a high quality of the finished products. FMS executed number of benefits in terms of reducing cost-increased utilization of machine-condensed work-in -process levels-etc. However-there are a number of problems faced during the life cycle of an FMS and these functions are classified into: design-planning-scheduling-and controlling.

Revised Manuscript Received on February 05, 2020.

* Correspondence Author

Dr. M. Nageswara Rao *, Department of Mechanical Engineering, K L E F University, Guntur, AP, India. E-mail: medikondu1979@gmail.com Varakumari S., Department of E C E, K L E F University, Guntur, AP, 522501, India. Email: Varakumari3@gmail.com

P. Manohar, Department of Mechanical Engineering, K L E F University, Guntur, AP, India Email: manohar7093@gmail.com

B. Madesh, Department of Mechanical Engineering, K L E F University,Guntur,AP, India. E-mail: baratammadesh@gmail.com

P. Naveen Krishna, Department of Mechanical Engineering, K L E F University, Guntur, AP, India E-mail: pnaveen0305@gmail.com

R. Suraj Krishna Sai, Department of Mechanical Engineering, K L E F University, Guntur, AP, India. E-mail: surajkrishnasai@gmail.com

(C) The Authors. Published by Blue Eyes Intelligence Engineering and Sciences Publication (BEIESP). This is an open access article under the CC BY-NC-ND license (http://creativecommons.org/licenses/by-nc-nd/4.0/)
In particular-the scheduling task and control problem during the manufacturing operation are of importance owing to the dynamic nature of the FMS in respect of flexible parts-tools-assignments. In FMS scheduling-decisions that need to be made include not only sequencing of jobs on machines but also the routing of the jobs through the system. Apart from the machines-other resources in the system like Automated Guided Vehicle (AGV) and Automated Storage/Retrieval System (AS/RS) must be considered The AGVs effectiveness depends on vehicle management system.

\section{LITERATURE REVIEW}

\section{A. Simultaneous scheduling in FMS}

In simultaneous scheduling-the real time as well as the off-line scheduling is taken into account. Bilge and Ulusoy [1] exploited the interactions between the machine and AGVs scheduling simultaneously. The material transfer between machines is done by a number of identical AGVs which are not allowed to return to the load/unload station after each delivery. Abdelmaguid et al.[2] suggested a hybrid GA for the problem of simultaneous scheduling of machines and AGVs in FMS with minimizing the makespan. The algorithm is applied to a set of 82 test problems-which was constructed by other researchers-and the comparison of the results indicates the superior performance with the developed coding. Reddy and Rao [3] studied the simultaneous scheduling problem with makespan-mean flow time and mean tardiness as an criterion. The proposed hybrid GA for FMS scheduling problems yielded better results when compared to other algorithms. Gnanavelbabu et al. [4] examined the scheduling of machines and AGVs simultaneously in FMS using differential evaluation with makespan minimization. The algorithm is tested by using test problems proposed by various researchers and the makespan obtained by the algorithm is compared with that obtained by other researchers are analyzed. Anandaraman et al. [5] presented a solution for the simultaneous scheduling problem by evolutionary approach in FMS with vehicles and robots with the objectives to minimize the makespan-mean flow time and mean tardiness. The scheduling optimization is carried out using metaheuristic algorithm. The algorithms are applied for test problems taken from the literature and the results obtained using the two algorithms are compared. Nouri et al. [6] introduced the clustered holonic multiagent model using metaheuristic for simultaneous scheduling of machines and transport robot in FMS. 
Computational results are presented using three sets of benchmark instances in the literature. New upper bounds are found-showing the effectiveness of the presented approach. Md Kamal et al. [7] Flexible Job Shop Scheduling Problem (FJSSP) is an extension of the classical Job Shop Scheduling Problem (JSSP).

Keeping in view this aspect-this article presents a comprehensive literature review of the FJSSPs solved using the GA. The survey is further extended by the inclusion of the hybrid GA (hGA). Nageswararao et al [8]

\section{SIMULTANEOUS SCHEDULING PROBLEMS IN FMS}

\section{A. Problem structure}

Bilge and Ulusoy (1995) proposed a numerical example for simultaneous scheduling of machines and AGVs in FMS environment which includes four layouts-ten jobsets process times and travel time data as an input

\section{B. Objective function}

Operation completion time $=\mathrm{Oij}=\mathrm{Tij}+\mathrm{Pij}$

$\mathrm{T}_{\mathrm{ij}}=$ Traveling time for $\mathrm{j}^{\text {th }}$ operation and $\mathrm{i}^{\text {th }}$ job

$\mathrm{P}_{\mathrm{ij}}=$ operation processing time

\section{Optimization parameters considered:}

Population Size $=$ Double the no of operations Iterations completed $=1000$

\section{Vehicle scheduling methodology}

Jobs are scheduled based on the operation sequence derived by the algorithms. The problem considered needs scheduling of material handling system along with that of machines. To obtain the makespan value for a given sequence of operations the following procedural steps are implemented.

Step 1: To Consider the machine number (M.No) of the given sequence for the job.

Step 2: To Select the AGV

Step 3: To identify the vehicle previous location (VPL)-previous operation machine number (POMN)-vehicle ready time (VRT) and previous operation completion time (POCT)

Step 4: To calculate vehicle empty trip time (VET) using $\mathrm{VET}=\mathrm{VRT}+\mathrm{VPL}$ to POMN

Step 5: Finding out the maximum from POCT and VET.

Step 6: Obtaining the total travel time of vehicle (TT) using

TT=VET+ POMN to M.No.

Step 7: To know the machine readiness time (MRT).

Step 8: To Identify the maximum of TT and MRT.

Step 9: Maximum time (from step 8) is added to process time to get the operational completion time.

Step 10: Repeated the steps from 2 to 9 for all other operations.

Step 11: To Identify the maximum operational completion time-which represents the possible completion time (makespan) of given job set.

\section{ANT COLONY OPTIMIZATION}

Ant Colony Optimization (ACO) was developed by $\mathrm{M}$. Dorigo (1992). The name and inspiration by the behavior of real ants. The steps involved in ACO are given below:

1. Consider the Job Set
2. Generate randomly an initial population of Ants and calculate its Operational Completion Time for all randomly generated Ants sequences

3. Determine Pheromone Matrix

$$
\tau_{i j}=\rho \tau^{1}{ }_{i j}+\Delta \tau_{i j}
$$

Where $i=1-2-\ldots \ldots \ldots . . . b$ position of sequence represented by ants

$\mathrm{b}=$ No of partial schedule

$\mathrm{j}=1-2-\ldots \ldots \ldots$. $\mathrm{b}$ is the index partial schedule

$\rho=$ Pheromone Evaporation Rate (0 to 1 )

$\tau_{i j}^{1}=$ Pheromone Value in the previous iteration

$\Delta \tau_{i \tilde{i}}=$ Change in the pheromone value

The value of $\Delta \tau_{i j}$ is calculated

$$
\Delta \tau_{i j}=\frac{1}{k_{i j}} \sum_{k=1}^{p_{\text {size }}} \frac{Q}{o b j(k)}
$$

Where $p_{\text {size }}=$ Size of population of ants $o b j(k)=$ objective function

$k_{i j}=$ Number of ants in the population

$Q=$ Given constant (1000)

4. Update Pheromone-by changing of ants in probabilistic manner

$$
P_{i j}=\frac{\left(\tau_{i j}\right)^{\alpha}\left(\eta_{i j}\right)^{\beta}}{\sum\left(\tau_{i k}\right)^{\alpha}\left(\eta_{i k}\right)^{\beta}}
$$

Where $\tau_{i \tilde{j}}=$ Value taken from the pheromone matrix $\eta_{i j}=$ Reciprocal of the total time taken by ants

$\alpha_{-} \beta$ are constants $\alpha=0.5$ to $0.9 \quad \beta=0.1$ to 0.4

5. Consequently-in each iteration-the best ants are built;

6. Repeat steps 2-5above until an acceptable solution is found or you reach some maximum number of iterations.

\section{A. Algorithm to Optimal Scheduling Problem:}

For implementation of ACO-Job set 1 and Layout 3 are considered as an example

The ACO is explained in the following steps for the job set 1 : Step 1: Considering the job set

\begin{tabular}{|l|l|l|l|l|l|}
\hline \multicolumn{5}{|c|}{ Lob set: 1 } \\
\hline Job 1 & Job 2 & Job 3 & Job 4 & Job 5 \\
\hline M1-M2-M4 & M1-M3-M2 & M3-M4-M1 & M4-M2 & M3-M1 \\
\hline 1-2-3 & $4-5-6$ & $7-8-9$ & $10-11$ & $12-13$ \\
\hline
\end{tabular}

In ACO for the operation in a job set numbers are assigned serially.

Step 2: Generating the Population size (double the number of operations) randomly by using precedence relation i.e.-operation of the same job set must be in increasing order but anywhere in the sequence. These are presented in table 1 and the steps discussed in 3.4 are implemented to identify the maximum operational completion time (makespan) for each sequence. 
Table 1: Generated population size for the ACO

\begin{tabular}{|c|c|c|}
\hline S.No & Sequence & Makespan \\
\hline 1 & $1-12-10-4-7-13-2-5-11-8-9-6-3$ & 88 \\
\hline 2 & $1-4-10-7-12-2-11-8-13-5-9-6-3$ & 92 \\
\hline 3 & $12-4-10-7-1-2-13-5-11-8-3-6-9$ & 92 \\
\hline 4 & $1-10-7-12-4-2-13-11-5-8-6-3-9$ & 96 \\
\hline 5 & 1-12-4 -7-10 -13-2-5-8-11-6-3-9 & 96 \\
\hline 6 & $4-1-10-7-12-2-13-8-11-5-9-6-3$ & 98 \\
\hline 7 & 12-7-4-10 -1-13-5-2-8-11-6-3-9 & 98 \\
\hline 8 & 10-7-1-4-12-2-13-11-5-8-9-3-6 & 98 \\
\hline 9 & 12-1-10-4-7-5-2-11-8-13-3-9-6 & 98 \\
\hline 10 & 12-7-1-10-4-13-5-2-8-11-6-3-9 & 98 \\
\hline 11 & 12-7-1-4-10-2-8-13-5-11-9-3-6 & 100 \\
\hline 12 & 12-7-1-10-4-8-13-11-2- 5-6-9-3 & 102 \\
\hline 13 & 7-1-10-4-12-13-2-8-5-11-9-3-6 & 102 \\
\hline 14 & 12-1-7-10-4-13-2-11-8-5- 9-3-6 & 102 \\
\hline 15 & 1-10-4-7-12-5-13-2-8-11-3-6-9 & 104 \\
\hline 16 & 1-10-4-12-7-8 -11-13-5-2-3-9-6 & 104 \\
\hline 17 & 12-7-4-1-10-8-13-5-2-11- 3-6-9 & 106 \\
\hline 18 & 12-1-4-7-10-5-8-2-13-11- 9-3-6 & 106 \\
\hline 19 & $12-1-10-7-4-11-5-2-8-13-9-6-3$ & 106 \\
\hline 20 & 10-7-12-1-4-13-11-8-2-5- 6-3-9 & 107 \\
\hline 21 & 10-12-4-7-1-13-11-8-2-5- 3- 6-9 & 107 \\
\hline 22 & 7-4-10-1 -12-8-13-11-5-2- 3-6-9 & 107 \\
\hline 23 & 10-12-1-7-4-8-5-11-2-13- 3-9-6 & 112 \\
\hline 24 & 1-7-4-12-10-5-8-13-11-2- 3-6-9 & 114 \\
\hline 25 & 1-7-12-4-10-11-13-2-5-8- 9-3-6 & 116 \\
\hline 26 & $4-1-12-7-10-8-11-13-2-5-9-6-3$ & 116 \\
\hline
\end{tabular}

From the above table it can be interpreted that in $1^{\text {st }}$ sequence-number ' 1 ' represents $1^{\text {st }}$ operation on the job no 1 and similarly number ' 12 ' represents the $1^{\text {st }}$ operation on job no 5 . Similarly-number ' 6 ' represents $3^{\text {rd }}$ operation on job no 2 and so on.

Step 3: Determine Pheromone Matrix for the randomly generated sequences, these are presented in Table 2

In the ACO the pheromone matrix is determined in the following

way $\tau_{i j}=\rho \tau^{1}{ }_{i j}+\Delta \tau_{i j}$

For example, consider sequence 1 and Sequence 2 for finding the pheromone matrix

$\tau_{i j \tilde{i}}=0.5 * 88+(1 / 26(1000 / 2567)=44.01 \sim 44$ similarly

Table 2: Pheromone Matrix for initial ten sequences

\begin{tabular}{|l|l|l|l|l|l|l|l|l|l|l|}
\hline $\begin{array}{r}\text { Fron } \\
\text { To }\end{array}$ & 1 & 2 & 3 & 4 & 5 & 6 & 7 & 8 & 9 & 10 \\
\hline 1 & 0 & 44 & 48 & 52 & 52 & 54 & 54 & 54 & 54 & 54 \\
\hline 2 & 50 & 0 & 46 & 50 & 50 & 52 & 52 & 52 & 52 & 52 \\
\hline 3 & 50 & 46 & 0 & 50 & 50 & 52 & 52 & 52 & 52 & 52 \\
\hline 4 & 56 & 52 & 48 & 0 & 48 & 50 & 50 & 50 & 50 & 50 \\
\hline 5 & 56 & 52 & 48 & 48 & 0 & 50 & 50 & 50 & 50 & 50 \\
\hline 6 & 59 & 55 & 55 & 51 & 51 & 0 & 49 & 49 & 49 & 49 \\
\hline 7 & 59 & 55 & 55 & 51 & 51 & 49 & 0 & 49 & 49 & 49 \\
\hline 8 & 59 & 55 & 55 & 51 & 51 & 49 & 49 & 0 & 49 & 49 \\
\hline 9 & 59 & 55 & 55 & 51 & 51 & 49 & 49 & 49 & 0 & 49 \\
\hline 10 & 59 & 55 & 55 & 51 & 51 & 49 & 49 & 49 & 49 & 0 \\
\hline
\end{tabular}

Step 4: Update Pheromone-by changing of ants in probabilistic manner

$$
P_{i j}=\frac{(88)^{0.85}(0.0113)^{0.65}}{(2567)^{0.85}(0.0003)^{0.65}}=0.600 \sim 1
$$

Based on $P_{i j \bar{j}}$ values change the sequence to get the updated make span values, these are presented in table 3

Table3: Updated Population size for the ACO

\begin{tabular}{|c|c|c|}
\hline S.No & Sequence & Makespan \\
\hline 1 & $1-12-10-4-7-13-2-5-11-8-9-6-3$ & 88 \\
\hline 2 & $10-4-12-7-1-11-13-5-2-8-9-6-3$ & 88 \\
\hline 3 & $7-10-4-12-1-11-8-5-13-2-6-9-3$ & 88 \\
\hline 4 & $4-1-10-12-7-2-13-11-5-8-6-9-3$ & 88 \\
\hline 5 & $7-4-10-1-12-5-2-8-11-13-3-9-6$ & 90 \\
\hline 6 & 1-4-10-7-12-2-11-8-13-5-9-6-3 & 92 \\
\hline 7 & 12-4-10-7-1-2-13-5-11-8-3-6-9 & 92 \\
\hline 8 & 1-10-4-7-12-2-11-8-13-5-9-6-3 & 92 \\
\hline 9 & 12-4-10-7-1-13-2-5-8-11- 3-9-6 & 92 \\
\hline 10 & 1-10-4-12-7-2-8-5-11-13-3-6-9 & 94 \\
\hline 11 & $12-4-10-1-7-2-5-8-11-13-6-9-3$ & 94 \\
\hline 12 & 1-7-10-12-4-2-13-11-5-8-6-3-9 & 94 \\
\hline 13 & 12-10-1-7-4-13-5-2-8-11-6-3-9 & 94 \\
\hline 14 & $1-12-4-7-10-13-2-5-8-11-6-3-9$ & 96 \\
\hline 15 & 10-4-7-12-1-13-2-8-11-5-6-9-3 & 96 \\
\hline 16 & 4-12-10-7-1-2-13-8-11-5-9-6-3 & 96 \\
\hline 17 & 10-7-1-4-12-2-13-11-5-8-9-3-6 & 98 \\
\hline 18 & 7-4-1-10-12-13-5-2-11-8-6-9- 3 & 98 \\
\hline 19 & $1-10-7-4-12-5-2-8-13-11-6-3-9$ & 98 \\
\hline 20 & 12-10-1-4-7-2-8-13-5-11-9-3-6 & 98 \\
\hline 21 & $10-7-1-12-4-8-5-11-2-13-3-9-6$ & 98 \\
\hline 22 & $4-10-1-12-7-13-11-5-2-8-6-9-3$ & 100 \\
\hline 23 & $4-12-10-1-7-13-11-2-5-8-9-3-6$ & 100 \\
\hline 24 & 12-10-1-7-4-8-13-11-2-5-6-9-3 & 100 \\
\hline 25 & 10-7-12-1-4-13-11-8-2-5-6-3-9 & 107 \\
\hline 26 & 10-12-4-7-1-13-11-8-2-5-3-6-9 & 107 \\
\hline
\end{tabular}

Step 5: the improved make span values in step 4 will become input for the next iteration which starts from step 2. This process will continue till acceptable solution is found within the specified limits ( in the present case 1000 iterations).

Step 7: Receptor editing:

The editing of the sequence in the population after the comparison process is known as receptor editing. In this process several worst makespan value sequences are eliminated from the population and randomly generated sequences are added in those places. After editing the sequences in the population-the new population has gone to next iteration until termination criterion is reached.

Step 8: Termination criterion:

The process of comparison is repeated till the termination criterion is satisfied.

Several termination criteria are available in the literature like-repeating the procedure for number of generations-running the algorithm for a fixed duration of time-and stopping the simulation when there is no improvement in fitness for the last "g" generations.

Published By:

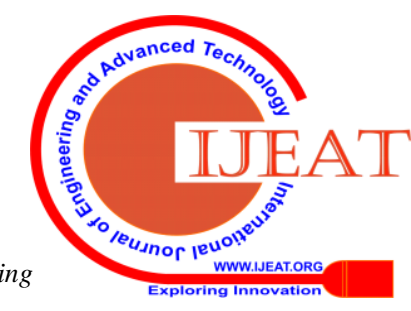




\section{Simultaneous Scheduling of Machines and AGVs in FMS Through Ant Colony Optimization Algorithm}

In this work the first criterion viz.-repeating the procedure for number of generations is taken as the termination criterion.

Step 9: The evaluated values of different parameters in arriving at the makespan after 1000 iterations for the best sequence is presented in table 4.

Table.4: Operations schedule through ACO:

\begin{tabular}{|c|c|c|c|c|c|c|}
\hline $\begin{array}{l}\text { Operati } \\
\text { on } \\
\text { Number }\end{array}$ & $\begin{array}{l}\text { Machin } \\
\text { e } \\
\text { Number }\end{array}$ & $\begin{array}{l}\text { Vehicl } \\
\text { e } \\
\text { Numbe } \\
\text { r }\end{array}$ & $\begin{array}{l}\text { Travel } \\
\text { Time }\end{array}$ & $\begin{array}{l}\text { Job } \\
\text { Rea } \\
\text { ch }\end{array}$ & $\begin{array}{l}\text { Job } \\
\text { Ready }\end{array}$ & $\begin{array}{l}\text { Make } \\
\text { Span }\end{array}$ \\
\hline 4 & 1 & 1 & 0 & 2 & 2 & 22 \\
\hline 10 & 4 & 2 & 0 & 12 & 12 & 26 \\
\hline 7 & 3 & 1 & 14 & 24 & 24 & 36 \\
\hline 12 & 3 & 2 & 14 & 24 & 36 & 46 \\
\hline 1 & 1 & 1 & 28 & 30 & 30 & 38 \\
\hline 5 & 3 & 1 & 30 & 38 & 46 & 56 \\
\hline 11 & 2 & 2 & 26 & 32 & 32 & 50 \\
\hline 8 & 4 & 1 & 38 & 40 & 40 & 48 \\
\hline 2 & 2 & 1 & 44 & 46 & 50 & 66 \\
\hline 13 & 1 & 2 & 46 & 52 & 52 & 67 \\
\hline 9 & 1 & 1 & 54 & 58 & 67 & 82 \\
\hline 6 & 2 & 2 & 60 & 68 & 68 & 86 \\
\hline 3 & 4 & 1 & 66 & 74 & 74 & 86 \\
\hline
\end{tabular}

Table 4 shows operation scheduling of through ant colony optimization algorithm for job set 1 layout 3 is shown. From the table it is observed that operation 4 on machine 1 is completed by 22 min hence $1^{\text {st }}$ operation will start after completion of $4^{\text {th }}$ operation on machine 1 . In case of job set 1 and layout 3 operation 10 on machine 4 is completed by 26 min hence $11^{\text {th }}$ operation on machine 2 will start after completion of $10^{\text {th }}$ operation on machine 4. Similarly-no operation on the particular machine will start until the operation on the machine is completed. From the vehicle heuristic algorithm for first two operations AGVs are selected randomly in case of third operation AGV ' 1 ' is selected basing on the availability of AGV with minimum travel time this constraint will be taking care in the algorithm-for job set 7 and layout 3 the operational completion time (makespan) is 86

\section{RESULT AND DISCUSSSION}

Computations for completion time for different combinations of job sets and layouts for ant colony optimization algorithm-Priority rules (FCFS-SPT-LPT-Nageswararao et al. 2017)-Heuristic (NEH-Prakash babu et al-2018-FUZZY-P. B. Kanakavalli et al-2018) with $\mathrm{t} / \mathrm{p}>0.25$ are done and tabulated in 5. A code is used to designate the example problems which are given in the first column. The digits that follow 1.1 indicate the job set and the layout. In $\mathrm{t} / \mathrm{p}$ ratio $<0.25$ table another digit is appended to the code. Here-having a 0 or 1 as the last digit implies that the process times are doubled or tripled-respectively-where in both cases travel times are halved.

Table 5. Comparison of make span values (for $\mathbf{t} / \mathbf{p}>\mathbf{0 . 2 5}$ )

\begin{tabular}{|l|l|l|l|l|l|l|l|}
\hline Job. No & $\mathrm{t} / \mathrm{p}$ & FCFS & SPT & LPT & NEH & FUZZY & ACO \\
\hline 1.1 & 0.59 & 173 & 193 & 177 & 165 & 208 & 96 \\
\hline 2.1 & 0.61 & 158 & 158 & 177 & 169 & 170 & 114 \\
\hline 3.1 & 0.59 & 202 & 224 & 198 & 195 & 211 & 120 \\
\hline 4.1 & 0.91 & 263 & 267 & 264 & 260 & 268 & 124 \\
\hline 5.1 & 0.85 & 148 & 164 & 148 & 147 & 174 & 89 \\
\hline 6.1 & 0.78 & 231 & 240 & 227 & 225 & 233 & 139 \\
\hline 7.1 & 0.78 & 195 & 210 & 201 & 173 & 196 & 134 \\
\hline 8.1 & 0.58 & 261 & 261 & 266 & 261 & 261 & 185 \\
\hline 9.1 & 0.61 & 270 & 277 & 268 & 259 & 273 & 124 \\
\hline 10.1 & 0.55 & 308 & 308 & 310 & 305 & 315 & 174 \\
\hline 1.2 & 0.47 & 143 & 173 & 165 & 147 & 188 & 82 \\
\hline
\end{tabular}

\begin{tabular}{|l|l|l|l|l|l|l|l|}
2.2 & 0.49 & 124 & 124 & 130 & 116 & 127 & 89 \\
\hline 3.2 & 0.47 & 162 & 188 & 160 & 154 & 178 & 96 \\
\hline 4.2 & 0.73 & 217 & 223 & 224 & 215 & 232 & 92 \\
\hline 5.2 & 0.68 & 118 & 144 & 131 & 117 & 156 & 73 \\
\hline 6.2 & 0.54 & 180 & 169 & 165 & 158 & 175 & 115 \\
\hline 7.2 & 0.62 & 149 & 160 & 149 & 136 & 139 & 97 \\
\hline 8.2 & 0.46 & 181 & 181 & 198 & 181 & 181 & 159 \\
\hline 9.2 & 0.49 & 250 & 249 & 244 & 205 & 249 & 106 \\
\hline 10.2 & 0.44 & 290 & 288 & 287 & 274 & 274 & 153 \\
\hline 1.3 & 0.52 & 145 & 175 & 167 & 145 & 190 & 86 \\
\hline 2.3 & 0.54 & 130 & 130 & 136 & 122 & 133 & 100 \\
\hline 3.3 & 0.51 & 160 & 190 & 162 & 158 & 176 & 102 \\
\hline 4.3 & 0.8 & 233 & 237 & 230 & 226 & 234 & 99 \\
\hline 5.3 & 0.74 & 120 & 146 & 133 & 117 & 156 & 76 \\
\hline 6.3 & 0.54 & 182 & 171 & 167 & 160 & 177 & 121 \\
\hline 7.3 & 0.68 & 155 & 166 & 151 & 138 & 141 & 105 \\
\hline 8.3 & 0.5 & 183 & 183 & 200 & 183 & 183 & 169 \\
\hline 9.3 & 0.53 & 252 & 251 & 246 & 207 & 251 & 111 \\
\hline 10.3 & 0.49 & 293 & 294 & 293 & 280 & 280 & 158 \\
\hline 1.4 & 0.74 & 189 & 207 & 189 & 189 & 228 & 108 \\
\hline 2.4 & 0.77 & 174 & 174 & 174 & 169 & 190 & 124 \\
\hline 3.4 & 0.74 & 220 & 250 & 212 & 213 & 225 & 133 \\
\hline 4.4 & 1.14 & 301 & 301 & 298 & 298 & 294 & 134 \\
\hline 5.4 & 1.06 & 171 & 189 & 171 & 171 & 193 & 98 \\
\hline 6.4 & 0.78 & 249 & 252 & 237 & 234 & 243 & 148 \\
\hline 7.4 & 0.97 & 217 & 242 & 151 & 192 & 232 & 155 \\
\hline 8.4 & 0.72 & 285 & 285 & 200 & 285 & 285 & 195 \\
\hline 9.4 & 0.76 & 292 & 311 & 290 & 285 & 295 & 126 \\
\hline 10.4 & 0.69 & 350 & 350 & 345 & 345 & 353 & 183 \\
\hline & & & & & & & \\
\hline
\end{tabular}

In the optimal sequence of machines and AGVs are determined by using FCFS-SPT-LPT-NEH-FUZZY and ACO for $\mathrm{T} / \mathrm{P}>0.25$ are shown in Table 5 . From Table 5 it can be observed that-out of 40 problems- 40 problems give better results using ACO when compared with all other five algorithms (100\%). Computations for completion time for different combinations of job sets and layouts for ant colony optimization algorithm-Priority rules (FCFS -SPT -LPT Nageswararao et al. 2017)-Heuristic (NEH-Prakash babu et al-2018-FUZZY-P. B. Kanakavalli et al-2018) with t/p > 0.25 are done and tabulated in 6.

Table 6. Comparison of make span values (for $t / p>0.25$ )

\begin{tabular}{|l|l|l|l|l|l|l|l|}
\hline Job.No & $\mathrm{t} / \mathrm{p}$ & FCFS & SPT & LPT & NEH & FUZZY & ACO \\
\hline 1.10 & 0.15 & 207 & 248 & 252 & 207 & 278 & 126 \\
\hline 2.10 & 0.15 & 217 & 217 & 225 & 185 & 208 & 148 \\
\hline 3.10 & 0.15 & 257 & 327 & 282 & 255 & 300 & 162 \\
\hline 4.10 & 0.15 & 303 & 328 & 317 & 277 & 352 & 123 \\
\hline 5.10 & 0.21 & 152 & 190 & 187 & 154 & 225 & 102 \\
\hline 6.10 & 0.16 & 304 & 281 & 297 & 272 & 294 & 200 \\
\hline 7.10 & 0.19 & 231 & 240 & 264 & 213 & 235 & 137 \\
\hline 8.10 & 0.14 & 338 & 338 & 347 & 332 & 338 & 292 \\
\hline 9.10 & 0.15 & 390 & 367 & 359 & 324 & 382 & 182 \\
\hline 10.10 & 0.14 & 452 & 429 & 444 & 398 & 393 & 264 \\
\hline 1.20 & 0.12 & 194 & 238 & 246 & 197 & 268 & 123 \\
\hline 2.20 & 0.12 & 194 & 194 & 206 & 167 & 187 & 143 \\
\hline 3.20 & 0.12 & 241 & 311 & 270 & 241 & 285 & 159 \\
\hline 4.20 & 0.12 & 285 & 312 & 298 & 248 & 340 & 116 \\
\hline 5.20 & 0.17 & 142 & 180 & 184 & 143 & 217 & 100 \\
\hline 6.20 & 0.12 & 292 & 260 & 284 & 251 & 277 & 201 \\
\hline 7.20 & 0.15 & 212 & 218 & 249 & 188 & 210 & 136 \\
\hline 8.20 & 0.11 & 306 & 319 & 334 & 306 & 306 & 287 \\
\hline
\end{tabular}




\begin{tabular}{|l|l|l|l|l|l|l|l|}
9.20 & 0.12 & 380 & 355 & 347 & 309 & 372 & 179 \\
\hline 10.20 & 0.11 & 445 & 423 & 439 & 388 & 384 & 259 \\
\hline 1.30 & 0.13 & 195 & 239 & 247 & 196 & 169 & 122 \\
\hline 2.30 & 0.13 & 197 & 197 & 209 & 170 & 190 & 146 \\
\hline 3.30 & 0.13 & 240 & 312 & 271 & 240 & 284 & 160 \\
\hline 4.30 & 0.13 & 292 & 317 & 301 & 255 & 339 & 117 \\
\hline 5.30 & 0.18 & 141 & 181 & 183 & 143 & 216 & 99 \\
\hline 6.30 & 0.24 & 296 & 261 & 285 & 252 & 278 & 200 \\
\hline 7.30 & 0.17 & 215 & 221 & 250 & 191 & 213 & 137 \\
\hline 8.30 & 0.13 & 307 & 320 & 335 & 307 & 307 & 288 \\
\hline 9.30 & 0.13 & 381 & 356 & 348 & 310 & 373 & 180 \\
\hline 10.30 & 0.12 & 448 & 426 & 442 & 391 & 387 & 260 \\
\hline 1.40 & 0.18 & 213 & 255 & 254 & 213 & 288 & 124 \\
\hline 2.41 & 0.13 & 307 & 307 & 319 & 267 & 293 & 217 \\
\hline 3.40 & 0.18 & 261 & 330 & 282 & 258 & 305 & 165 \\
\hline 3.41 & 0.12 & 370 & 476 & 411 & 310 & 435 & 242 \\
\hline 4.41 & 0.19 & 434 & 471 & 451 & 393 & 504 & 177 \\
\hline 5.41 & 0.18 & 218 & 269 & 270 & 222 & 321 & 148 \\
\hline 6.40 & 0.19 & 310 & 288 & 299 & 275 & 303 & 213 \\
\hline 7.40 & 0.24 & 239 & 251 & 270 & 221 & 246 & 141 \\
\hline 7.41 & 0.16 & 329 & 344 & 385 & 224 & 332 & 208 \\
\hline 8.40 & 0.18 & 343 & 343 & 349 & 339 & 343 & 293 \\
\hline 9.40 & 0.19 & 396 & 379 & 370 & 325 & 388 & 182 \\
\hline 10.40 & 0.17 & 466 & 445 & 455 & 415 & 408 & 270 \\
\hline & & & & & & & \\
\hline
\end{tabular}

\section{ACKNOWLEDGMENT}

The authors greatly acknowledge the financial support from DST-SERB-Govt.of India (Sanction No: SB/EMEQ-501/2014) for carrying out this R \& D activity.

\section{REFERENCES}

1. U.Bilge \&G. Ulusoy, "A time window approach to simultaneous scheduling of machines and material handling system in an FMS". Journal of Operations Research, 43, 1995,pp.1058-1070.

2. T.F.Abdelmaguid, A.O. Nasef, B.A.Kamal \& M.F.Hassan, "A hybrid GA / heuristic approach to the simultaneous scheduling of machines and automated guided vehicles". International Journal of Production Research, 42, 2004 pp267-281.

3. B.S.P. Reddy, C.S.P Rao, "A hybrid multi-objective GA for simultaneous scheduling of machines and AGVs in FMS". International Journal of Advanced Manufacturing Technology, 31,2006, pp 602-613.

4. A.G. Babu, A.G., Jerald, J., Haq, N., Muthu V. Luxmi, \& T.P Vigneswaralu, "Scheduling of machines and automated guided vehicles in FMS using differential evolution". Int. J. Prod. Res, iFirst 2010 pp 1-17.

5. C.Anandaraman, A. Vikram M. Sankar, R. Natarajan, "Evolutionary approaches for scheduling a flexible manufacturing system with automated guided vehicles and robots". International Journal of Industrial Engineering Computations, 3, 2012, pp 627-648.

6. H.E .Nouri, O.B, Driss, \& K. Ghédira," Simultaneous scheduling of machines and transport robots in flexible job shop environment using hybrid metaheuristics based on clustered holonic multiagent model". Computers, 2016, pp 488-501.

7. K.M. Amjad et al, "Recent research trends in genetic algorithm based flexible job shop scheduling problems". Mathematical Problems in Engineering,2018, pp 1-32.

In the optimal sequence of machines and AGVs are determined by using FCFS-SPT-LPT-NEH-FUZZY and ACO for $\mathrm{T} / \mathrm{P}<0.25$ are shown in Table 6. From Table 6 it can be observed that out of 42 problems-42 problems give better results using SA when compared with all other five algorithms (100\%).

\section{CONCLUSION}

Flexible Manufacturing system is considered as better option to face the challenges of global competition. But for successful implementation efficient scheduling is essential. Scheduling of an FMS is a very difficult problem because of other consideration like material handling. In this work an attempt has been made to solve the problem of scheduling both the machines and AGVs simultaneously by metaheuristic algorithm the following conclusions are drawn from this work. Performances of Metaheuristic Algorithms are evaluated by considering 82 benchmark problems consisting of different job sets and layout configurations. From the comparison of these results ant colony algorithms yielded improved results in 82 problems.

\section{SCOPE OF FUTURE WORK}

In this research work Ant Colony metaheuristic Algorithms to solve simultaneous scheduling problems in FMS. There is scope for further research work in the following aspects: In FMS jobs are entered with different priorities and the problem can be made dynamic in nature. When required sequence needs to reschedule. The simultaneous scheduling problem can be extended further by including AS/RS system. Real time issues like traffic jamming-without buffer space-machine breakdown can also be considered.

Dr. M. Nageswara Rao Department of Mechanica Engineering, K L E F University, Guntur, AP, India.

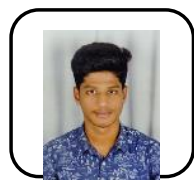

P. Manohar, Final year B.Tech Student, Department of Mechanical Engineering, K L E F University, Guntur,AP,India

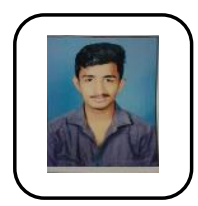

B. Madesh, Final year B.Tech Student, Department of Mechanical Engineering, K L E F University, Guntur, AP,India 
Simultaneous Scheduling of Machines and AGVs in FMS Through Ant Colony Optimization Algorithm

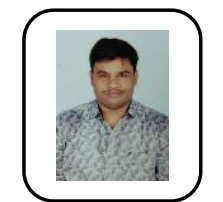

P. Naveen Krishna, Final year B.Tech Student, Department of Mechanical Engineering, K L E F University, Guntur, AP,India

R. Suraj Krishna Sai, Final year B.Tech Student, Department of Mechanical Engineering, $\mathrm{K}$ L E F University, Guntur, AP,India 